\title{
(C) OPEN ACCESS \\ Does adiposity mediate the relationship between socioeconomic position and non-allergic asthma in childhood?
}

\author{
Kate Marie Lewis, ${ }^{1}$ Hynek Pikhart, ${ }^{2}$ Joana Morrison ${ }^{2}$
}

\begin{abstract}
- Additional material is published online only. To view please visit the journal online (http://dx.doi.org/10.1136/ jech-2017-209722)
\end{abstract}

'Population, Policy and Practice, UCL Great Ormond Street Institute of Child Health, London, UK

${ }^{2}$ Research Department of Epidemiology and Public Health, University College London, London, UK

Correspondence to Kate Marie Lewis, PPP, UCL Great Ormond Street Institute of Child Health, London WC1N 1EH, UK; kate.lewis.14@ucl. ac.uk

Received 25 July 2017 Revised 4 January 2018 Accepted 8 January 2018 Published Online First 24 January 2018
Check for updates

To cite: Lewis KM

Pikhart H, Morrison J. J

Epidemiol Community Health 2018:72:390-396

\begin{abstract}
Background Despite its high prevalence, early onset and chronic nature, the causes of asthma are not clearly established. The present study examined a plausible but untested relationship in the development of nonallergic asthma; an asthma phenotype closely linked to deprivation and other preventable risk factors. Our aim was to determine the mediating role of adiposity in the relationship between socioeconomic position in infancy and non-allergic asthma emergence in mid-childhood. Methods To estimate the causal indirect effect of adiposity we applied the parametric g-computational procedure to 6203 singleton children from the UK Millennium Cohort Study. Adiposity was measured at age 7 by body mass index, waist circumference and waist circumference-to-height ratio. Children who developed non-allergic asthma between the age of 7 and 14 were compared with children without allergies or allergic asthma at these ages.
\end{abstract}

Results We found no evidence to suggest that adiposity is a mediator in the relationship between socioeconomic position and the development of non-allergic asthma in mid-childhood. After adjustment for risk factors, the direct effect of socioeconomic position remained; children in the lowest tertile of socioeconomic position had a $43 \%$ (OR $1.43,95 \% \mathrm{Cl} 1.38$ to 1.49$)$ greater odds of developing non-allergic asthma compared with the highest tertile.

Conclusions Adiposity at age 7 does not mediate the relationship between socioeconomic position and non-allergic asthma. The results suggest that improving socioeconomic conditions and promoting healthy weight are both important in reducing the development of nonallergic asthma in early to mid-childhood.

\section{INTRODUCTION}

Asthma is a chronic respiratory condition that develops in 15\% of the English population by their early teens. ${ }^{1}$ Annual National Health Service asthma care costs are estimated at almost $£ 1$ billion, which is the value before taking into account the cost of the numerous comorbidities and disadvantage associated with asthma across the life course. ${ }^{23}$ Despite the evident burden of asthma, efforts to prevent the development of the condition have been limited due, in part, to a restricted understanding of the preventable risk factors for asthma. ${ }^{4}$ Attempts to address the socioeconomic determinants of this chronic condition have had mixed results. Strina et $a l^{5}$ and others ${ }^{4}$ argue that differentiation between asthma with and without accompanying allergy is necessary due to the different causal mechanisms involved. Allergic asthma is linked to common allergens and comorbidities such as hay fever and eczema, whereas non-allergic asthma is not. ${ }^{7}$ This research will focus on non-allergic asthma, which, when examined independently from allergic asthma, has been consistently linked with lower socioeconomic circumstances and related risk factors. ${ }^{4-7}$ Epidemiological research from England previously identified asthma without allergy in $7.6 \%$ and asthma with allergy in $11.9 \%$ of children $7-8$ years of age. ${ }^{4}$

One important factor associated with both socioeconomic position and non-allergic asthma is adiposity. ${ }^{589}$ Markedly, pathways to both overweight/obesity and asthma embed at an early age. ${ }^{1011}$ Individuals with both asthma and obesity typically have worse health outcomes including poorer asthma control, worsened respiratory symptoms and lower self-reported quality of life. ${ }^{9} 12$ Although independent links between socioeconomic position, excessive bodyweight and non-allergic asthma have been made ${ }^{13}$ the potential association between the three factors has not yet, to the authors' knowledge, been investigated. In addition, research has typically focused on body mass index (BMI), when other indicators may determine adiposity more precisely in children. ${ }^{8} 1415$ The aim of this study was to determine whether adiposity is a mediator in the relationship between socioeconomic position in early childhood and the development of non-allergic asthma in mid-childhood. Previous research on similar topics used cross-sectional design, adult only samples and non-differentiation of asthma

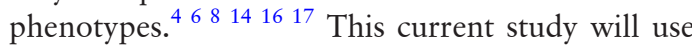
longitudinal cohort data to help improve understanding of mid-childhood adiposity as a target for intervention to reduce the inequity of this burdensome respiratory condition.

\section{DATA AND METHODS \\ Conceptual framework}

To establish the extent to which the socioeconomic effect on non-allergic asthma is mediated through adiposity, this study adopted a counterfactual-based approach to mediation analysis as described by VanderWeele. ${ }^{18}$ This framework decomposes the total effects of the exposure (in this case socioeconomic position) on the outcome (non-allergic asthma) into natural indirect and direct effects. The natural indirect effect captures the exposure-outcome effect that is due to the effect of the exposure on the mediator (adiposity), while the natural 
Table 1 Details of the MCS sample, by wave of study ${ }^{2022}$

\begin{tabular}{|c|c|c|c|c|c|c|}
\hline \multirow[b]{2}{*}{ Wave } & \multirow[b]{2}{*}{ Age * $^{*}$} & \multirow[b]{2}{*}{ Years conducted } & \multicolumn{2}{|c|}{ Productive sample } & \multirow{2}{*}{$\begin{array}{l}\text { Household response by } \\
\text { wave }(\%)\end{array}$} & \multirow{2}{*}{$\begin{array}{l}\text { Participated in all } \\
\text { previous waves }\end{array}$} \\
\hline & & & Children & Families & & \\
\hline 1 & 9 months & 2001-2002 & $19517 \dagger$ & $19244 \ddagger$ & 89.9 & - \\
\hline 2 & 3 years & 2004-2005 & 15808 & 15590 & 78.2 & 14898 \\
\hline 3 & 5 years & 2006-2007 & 15459 & 15246 & 79.2 & 13234 \\
\hline 4 & 7 years & 2008 & 14043 & 13857 & 81.1 & 11721 \\
\hline 5 & 11 years & 2012-2013 & 13469 & 13287 & 81.4 & 10448 \\
\hline 6 & 14 years & 2015 & 11884 & 11726 & 76.1 & 10411 \\
\hline
\end{tabular}

*Ages are approximate.

tIncluding 699 children recruited at wave 2

łIncluding 692 families recruited at wave 2 .

MCS, Millennium Cohort Study.

direct effect captures the exposure-outcome effect that does not pass through the mediator. To interpret the effects causally several strong confounding assumptions must be met ${ }^{18}$ : (1) control for exposure-outcome confounding; (2) control for mediator-outcome confounding; (3) control for exposure-mediator confounding; and (4) none of the mediator-outcome confounders are themselves affected by the exposure. While appropriate confounders will be applied, it is known that these assumptions are often violated in application and unmeasured confounding is likely present. ${ }^{19}$ We will evaluate the robustness of confounding assumptions through sensitivity analyses and in the discussion.

\section{Study population}

This study uses anthropometric and caregiver reported data from the Millennium Cohort Study (MCS); a prospective birth cohort study of children born in the UK between 2000 and 2002. To ensure a representation of the total UK population, while also adequately sampling children typically underrepresented in surveys, the MCS employed stratified sampling at the electoral ward level with oversampling of disadvantaged and ethnic minority children. ${ }^{20}$ Technical details about the design, sampling outcomes and purpose of the MCS are available elsewhere. $^{20-22}$ Table 1 shows the productive sample at each wave of the study.

The sample used in this current analysis is drawn from singleton cohort members who participated in the study at 9 months, 3,7 and 11 or 14 years old; $59.1 \%$ of baseline singletons. Children with a history of non-allergic asthma at age 7 were excluded to ensure cases of non-allergic asthma in our study emerged after the study mediators, which were also recorded at age 7. Children with allergies or allergic asthma at age 11 or 14 were also excluded to ensure a valid control group was used. ${ }^{23}$ See figure 1 for a complete flow chart of sample selection. After excluding participants without complete data on all study variables, the final sample size was 6203 . UK-level sampling weights were applied to the current analyses to adjust for sampling and attrition by wave $5 .^{24}$ All data were retrieved from the UK Data Service. $^{25}$

\section{Outcome measure}

Asthma was defined by caregiver report of wheezing in the last 12 months and/or asthma ever, and allergy by caregiver report of hay fever and/or eczema ever. There is no objective measure of allergy in the MCS; however, these questions are drawn from the standardised and validated International Study of Asthma and Allergies in Childhood questionnaire. ${ }^{26}$ Those meeting the definition for asthma without allergies by age 11 or 14 (for those with no asthma or allergies at age 11) were defined as non-allergic asthmatics. The control group comprised children with no asthma or allergies at ages 11 and 14 .

\section{Exposure}

A polychoric principal components analysis was used on eight economic and social factors reported by parents at wave 1 (cohort member aged 9 months) to develop a composite index of socioeconomic position. One factor, self-rated financial status, was excluded due to low correlations with other items $(<0.3)$, which led to a final index that accounted for $65.2 \%$ of the overall variance and had an eigenvalue of 4.56. The index comprises seven factors: age leaving full-time education, used to classify length of education (highest age used where parent responses differed); five-category National Vocational Qualification Classification, used to classify highest educational qualifications of parents; seven-category National Statistics Socio-economic Classification, used to rank current job type (highest classification used where parent responses differed); the Organisation for Economic Co-operation and Development below 60\% poverty

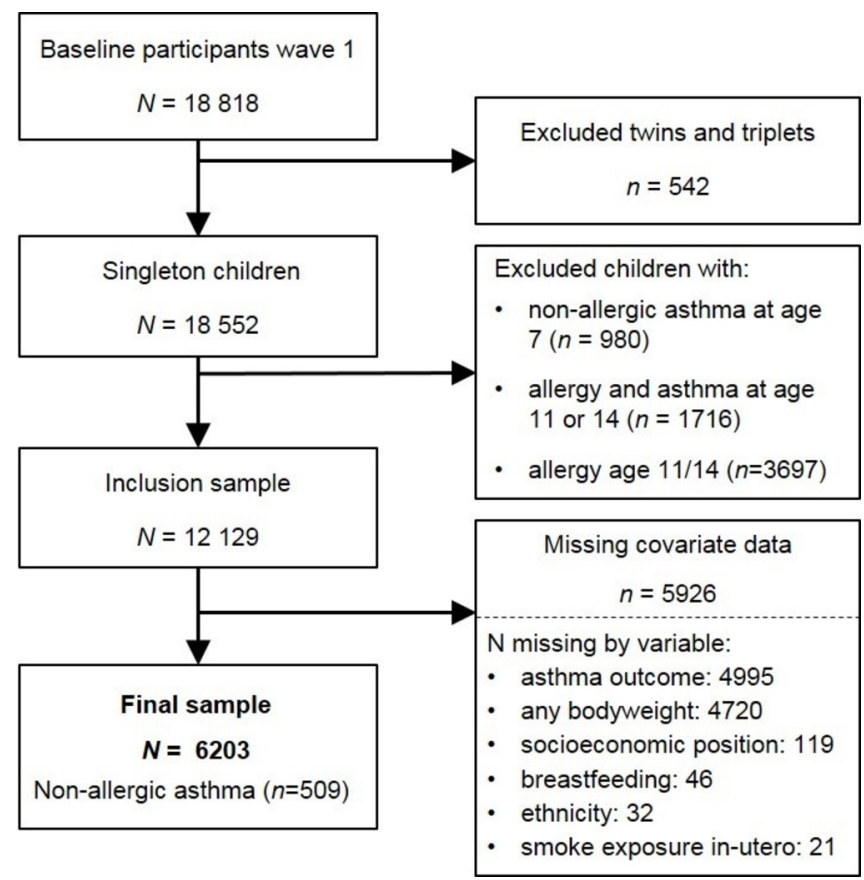

Figure 1 Flow chart of the sample selection. 


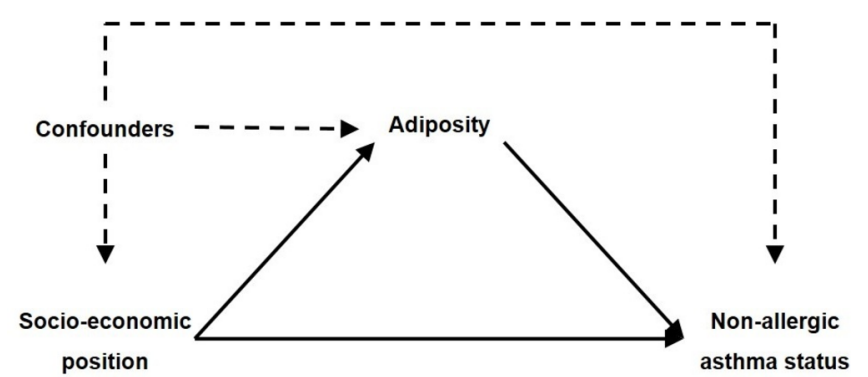

Figure 2 Hypothesised directed acyclic graph; adiposity measured in three separate models by body mass index (BMI) z-scores, waist-toheight ratio (WHtR) and waist circumference.

indicator, indicating households living in relative poverty; relationship status (married/cohabiting or other), to indicate family instability; housing tenure to define three categories of housing: own outright/mortgage, rent or other living circumstances (eg, live with parents, squat); and the number of rooms in the cohort member's home (equivalised). The index was transformed into tertiles for analyses.

\section{Potential mediators}

All body weight measurements were taken by trained interviewers in participants' homes at age 7 . BMI $\left(\mathrm{kg} / \mathrm{m}^{2}\right)$ was calculated by weight $(\mathrm{kg})$, measured using Tanita scales, and height (m), measured using Leicester stadiometers. The BMI scores were then transformed into sex-age-specific z-scores using the UK90 growth references ${ }^{27}$ to create a new variable with a mean of 0 and SD of 1 . Waist circumference (WC) was defined as the mean of two WC measurements $(\mathrm{cm})$ taken using a tape measure. Waist-to-height ratio (WHtR) was calculated by mean WC (cm) divided by height $(\mathrm{cm})$; expressed as one tenth of WHtR in results for interpretability. The three adiposity measurements were analysed as continuous variables to allow for potential quadratic effects on the outcome. Our hypothesised causal relationship between study variables is displayed in figure 2 .

\section{Potential confounders}

Confounders were selected on the basis of known associations with the exposure-mediator, mediator-outcome and/or exposure-outcome. All variables were reported by the child's mother at wave 1 when the cohort member was aged 9 months: child's sex (female/male); child's ethnicity split into six categories (White, Mixed, Indian, Pakistani and Bangledeshi, Black or Black British, or other ethnic group); firstborn (yes/no); caesarean section delivery (yes/no); prenatal exposure to tobacco smoke (yes/no); postnatal exposure to tobacco (yes/no); and duration of breast feeding ( $<1$ month, 1-3 months, $>3$ months).

\section{Analysis strategy}

Stata V.14 ${ }^{28}$ was used for all statistical analyses. Means (SDs) for continuous variables and percentages for other variables were used to describe the study sample and participants with missing data. Multivariable relationships between the exposure-mediators and exposure-outcome were explored using linear and logistic regression. Adiposity measures were tested in separate models due to multicollinearity, and were tested for non-linearity by adding a squared quadratic term $\left(y=a+b x+c x^{2}\right)$. Wald tests were used to assess linearity of variables, $\mathrm{P}<0.05$.

To estimate the hypothesised mediation effect of adiposity we used Stata command 'gformula', ${ }^{29}$ a parametric g-computation procedure implemented using Monte Carlo simulations. gformula offers flexibility in comparison to traditional mediation methods, including modelling non-linearities and allowing for mediator-outcome confounding and exposure-mediator interaction. Three models, each with a separate measure of body weight, were run to estimate the natural direct and indirect effects in the relationship between socioeconomic position and non-allergic asthma. Results are presented as ORs with 95\% CIs created from 1000 bootstrapped samples. gformula does not support svy weights; therefore, the final results were compared with weighted multivariable regressions. In the case of any significant mediation, Stata command 'medsens' was used to calculate how large the effect of an unmeasured mediator-outcome confounder needed to be to significantly alter the results.

\section{RESULTS}

Of the initial singleton cohort at wave 1, 51.1\% children meeting our study inclusion criteria had complete data. Missingness in the outcome was biased towards lower socioeconomic position, male sex and non-white ethnicities, $\mathrm{P}<0.01$. Characteristics of the final sample of 6203 children by socioeconomic group are viewable in table 2 . Overall, there were slightly more women in the weighted sample than men (51.1\%) and $86.4 \%$ of the cohort were white. At age 7, the average BMI was 0.33 SD higher than the UK90 reference standards, the average $W C$ was $57.0 \mathrm{~cm}$ and the average WHtR was 0.46 . Non-allergic asthma developed in $509(8.5 \%)$ children of the final study sample between ages 7 and 14.

Results of multivariable exposure-outcome analyses are presented in table 3 . Socioeconomic position was significantly associated with the development of non-allergic asthma after adjustment for confounders. Children in the lowest and middle socioeconomic groups had $77 \%$ (OR $1.77,95 \%$ CI 1.30 to 2.40 ) and $32 \%$ (OR 1.32, 95\% CI 1.01 to 1.70 ) increased odds of developing the outcome, respectively, compared with those in the highest group. All body weight measures had a significant non-linear association with non-allergic asthma, $\mathrm{P}<0.05$, with peak odds at the highest end of the distribution for WHtR and WC and the lowest for BMI z-scores (see figure A1-3 in supplementary file 1). There was a significant linear relationship between socioeconomic position and adiposity measures. After adjustment for ethnicity, moving from a higher to lower socioeconomic group was associated with: 0.06 increased BMI z-score $(\beta$ coefficient $0.06,95 \% \mathrm{CI} 0.01$ to 0.11$) ; 0.36 \mathrm{~cm}$ increase in WC ( $\beta$ coefficient $0.36,95 \% \mathrm{CI} 0.11$ to 0.62 ); and a $0.6 \%$ increase in WHtR ( $\beta$ coefficient $0.06,95 \%$ CI 0.04 to 0.07 ).

Table 4 presents the natural direct and indirect effects of socioeconomic position on non-allergic asthma. The relationship between socioeconomic position and non-allergic asthma was not explained by BMI or WHtR. A slight negative indirect effect of WC was present; however, this was considered unsubstantial as it accounted for only $0.4 \%$ of the total effect. Significant associations were present in the natural direct effects of high compared with low socioeconomic groups and, to a lesser extent, high compared with middle groups. Overall, with WHtR included as a mediator, children in the lowest socioeconomic group had a $46 \%$ increased odds (OR 1.46, 95\% CI 1.29 to 1.64 ) and children in the middle group had a $20 \%$ increased odds (OR $1.20,95 \%$ CI 1.01 to 1.44 ) of developing non-allergic asthma compared with children in the highest group. These results align to the findings of weighted multivariable analyses (table 3). No interaction between socioeconomic position and mediators was found, $P>0.05$. As no mediation effect was found, sensitivity analyses were not conducted. 
Table 2 Characteristics of the study population, by missing data and socioeconomic group

\begin{tabular}{|c|c|c|c|c|c|}
\hline & \multirow[b]{3}{*}{ Missing data sample* } & \multicolumn{4}{|c|}{ Final samplet } \\
\hline & & \multirow[b]{2}{*}{ Overall } & \multicolumn{3}{|c|}{ Socioeconomic position } \\
\hline & & & Low & Middle & High \\
\hline \multirow[t]{2}{*}{ Total unweighted (n) } & 5926 & 6203 & 1591 & 1987 & 2625 \\
\hline & $\%$ & $\%$ & $\%$ & $\%$ & $\%$ \\
\hline \multicolumn{6}{|l|}{ Socioeconomic position } \\
\hline Low & 41.9 & 27.5 & - & - & \\
\hline Middle & 34.5 & 32.6 & - & - & \\
\hline High & 23.6 & 39.9 & - & - & \\
\hline \multicolumn{6}{|l|}{ Sex } \\
\hline Female & 45.2 & 50.9 & 50.6 & 51.7 & 51.0 \\
\hline \multicolumn{6}{|l|}{ Ethnic group } \\
\hline White & & 78.2 & 86.4 & 77.1 & 88.2 \\
\hline Mixed & 2.7 & 2.7 & 4.5 & 1.6 & 2.3 \\
\hline Indian & 2.1 & 1.9 & 1.2 & 2.3 & 2.1 \\
\hline Pakistani and Bangladeshi & 8.4 & 5.0 & 10.1 & 5.0 & 1.5 \\
\hline Black or Black British & 6.0 & 2.7 & 5.0 & 1.8 & 1.7 \\
\hline Other & 2.7 & 1.3 & 2.0 & 1.2 & 0.9 \\
\hline \multicolumn{6}{|l|}{ Firstborn } \\
\hline Yes & 43.7 & 50.7 & 45.6 & 52.8 & 52.2 \\
\hline \multicolumn{6}{|l|}{ Caesarean birth } \\
\hline Yes & 16.5 & 19.6 & 14.2 & 20.0 & 22.7 \\
\hline \multicolumn{6}{|l|}{ Tobacco exposure in utero } \\
\hline Yes & 21.5 & 16.1 & 30.0 & 17.0 & 5.8 \\
\hline \multicolumn{6}{|l|}{ Tobacco exposure in infancy } \\
\hline Yes & 21.4 & 14.9 & 30.2 & 15.3 & 4.1 \\
\hline \multicolumn{6}{|l|}{ Breast fed (months) } \\
\hline$<1$ & 69.7 & 53.0 & 74.7 & 58.20 & 33.6 \\
\hline $1-3$ & 9.4 & 14.4 & 10.1 & 14.0 & 17.6 \\
\hline$>3$ & 21.0 & 32.7 & 15.2 & 27.8 & 48.8 \\
\hline \multicolumn{6}{|l|}{ Non-allergic asthma } \\
\hline \multirow[t]{2}{*}{ Yes } & 14.5 & 8.4 & 11.0 & 8.7 & 6.7 \\
\hline & Mean (SD) & Mean (SD) & Mean (SD) & Mean (SD) & Mean (SD) \\
\hline \multicolumn{6}{|l|}{ Adiposity measures } \\
\hline BMI z-score & $0.46(1.15)$ & $0.33(1.10)$ & $0.36(1.22)$ & $0.40(1.09)$ & $0.27(1.02)$ \\
\hline Waist & $57.5(6.4)$ & $57.0(5.8)$ & $57.4(6.6)$ & $57.2(6.0)$ & $56.7(5.1)$ \\
\hline WHtR & $0.46(0.04)$ & $0.46(0.04)$ & $0.47(0.04)$ & $0.46(0.04)$ & $0.46(0.04)$ \\
\hline
\end{tabular}

*Unweighted proportions and mean (SD) presented.

tWeighted proportions and mean (SD) presented.

BMI, body mass index; WHtR, waist-to-height ratio.

\section{DISCUSSION}

Using a large UK prospective birth cohort, this study found no evidence to suggest that body weight mediates the effect of socioeconomic position on non-allergic asthma development in children between 7 and 14 years of age. In multivariable analyses, socioeconomic position and high or low adiposity were significant but independent risk factors for non-allergic asthma.

This research adds to the increasing literature that links disadvantage with the emergence of non-allergic asthma. ${ }^{5713}$ An inverse association was found between socioeconomic position and non-allergic asthma, emphasising a social gradient to this health outcome. Prominently, this gradient persisted after adjustment for confounders. Previous research has found that higher rates of breast feeding and lower rates of maternal smoking during pregnancy account for the protective effect of high socioeconomic position $^{730}$; however, the effect of socioeconomic position held after adjustment for these factors in our study. Our findings may differ due to our composite measure of deprivation used, which encompasses more factors than the single measure of parental education used in previous research. ${ }^{57}$ These results suggest that improving the socioeconomic welfare of children and promoting healthy weight might both be important to reduce the development of non-allergic asthma in mid-childhood.

High and low body weights at age 7 were related to an increased risk of non-allergic asthma. Previous prospective studies have found an association of body weight with non-allergic asthma in children with high BMI (obesity). ${ }^{31} 32$ Overweight and BMI as a continuous measure have had mixed results in other research, with some finding an effect in one gender only. ${ }^{151631} \mathrm{BMI}$ has been found to be a useful marker in 
Table 3 Weighted multivariable associations between socioeconomic position and non-allergic asthma

\begin{tabular}{|c|c|c|c|c|}
\hline Adjustment & Socioeconomic position & OR & $(95 \% \mathrm{Cl})$ & $\mathrm{P}$ trend \\
\hline \multicolumn{5}{|l|}{ Confounders* } \\
\hline & High & 1.00 & (Baseline) & $<0.001$ \\
\hline & Middle & 1.32 & (1.01 to 1.70$)$ & \\
\hline & Low & 1.77 & (1.30 to 2.40$)$ & \\
\hline \multicolumn{5}{|c|}{ Confounders $^{*}+$ BMI z-score $+B M I$-score ${ }^{2}$} \\
\hline & High & 1.00 & (Baseline) & $<0.001$ \\
\hline & Middle & 1.28 & (0.99 to 1.66$)$ & \\
\hline & Low & 1.72 & (1.27 to 2.33$)$ & \\
\hline & BMI & 1.00 & (0.91 to 1.10$)$ & $<0.05$ \\
\hline & $+\mathrm{BMI}^{2}$ & 1.05 & (1.01 to 1.10$)$ & \\
\hline \multicolumn{5}{|c|}{ Confounders ${ }^{*}+W C+W C^{2}$} \\
\hline & High & 1.00 & (Baseline) & $<0.001$ \\
\hline & Middle & 1.32 & (1.02 to 1.71$)$ & \\
\hline & Low & 1.76 & (1.29 to 2.40$)$ & \\
\hline & WC & 0.80 & (0.65 to 0.98$)$ & $<0.05$ \\
\hline & $+W C^{2}$ & 1.00 & (1.00 to 1.00$)$ & \\
\hline \multicolumn{5}{|c|}{ Confounders ${ }^{*}+\mathrm{WHtR} \dagger+\mathrm{WHtR}^{2} \dagger$} \\
\hline & High & 1.00 & (Baseline) & $<0.001$ \\
\hline & Middle & 1.33 & (1.02 to 1.73$)$ & \\
\hline & Low & 1.77 & (1.30 to 2.40 ) & \\
\hline & WHtR & 0.04 & (0.00 to 0.57$)$ & $<0.05$ \\
\hline & $+\mathrm{WH} \mathrm{tR}^{2}$ & 1.39 & (1.08 to 1.80$)$ & \\
\hline
\end{tabular}

${ }^{*}$ Confounders are sex, ethnicity, caesarean, firstborn, smoke in utero, smoke infancy and breast feeding.

tWHtR values presented as $1 / 10 \mathrm{WHtR}$.

$\mathrm{BMI}$, body mass index; WC, waist circumference; WHtR, waist-to-height ratio.

adolescents and adults, but not in samples including only preadolescent children, ${ }^{8} 1532$ likely due to changes in body mass that naturally occur in young children. ${ }^{8}$ The current study also found that extreme WHtR, and to a lesser extent WC, either high or low, had a significant independent association with non-allergic asthma. An association between central obesity and asthma has been previously observed in adult samples ${ }^{1433} 34$; however, these studies failed to consider a non-linear relationship between the two conditions. Using a bioimpedance technique, Yiallouros et $a l^{15}$ found a U-shaped association between body fat percentage and asthma in preadolescent children. Our results suggest that using WHtR as a screening tool may be a simpler way to assess risk of non-allergic asthma in young populations. ${ }^{35}$
Employing g-computational techniques allowed us to model non-linear effects on a ratio scale in causal mediation analysis; however, strong assumptions accompany this method. ${ }^{36}$ Our results assume no further common causes of adiposity and non-allergic asthma apart from the confounders included. Indicators of early growth, for example, birth weight and gestational age, were not included although considered as confounders elsewhere. ${ }^{37}$ We did not account for these because our study focuses on the implications of weight status at age 7 , and the addition of earlier growth variables would have likely changed the interpretation of our results. In addition, since there was no substantial mediating effect of adiposity in our analyses, it is unlikely that additional confounders would change the results. We need also

Table 4 Pathway from SEP to non-allergic asthma

\begin{tabular}{|c|c|c|c|c|c|c|}
\hline & \multicolumn{3}{|c|}{ Low versus high socioeconomic position } & \multicolumn{3}{|c|}{ Middle versus high socioeconomic position } \\
\hline & $\mathrm{OR}^{*}$ & $(95 \% \mathrm{Cl})$ & $\mathbf{P}$ & $\mathrm{OR}^{*}$ & $(95 \% \mathrm{Cl})$ & $\mathbf{P}$ \\
\hline \multicolumn{7}{|c|}{ BMI z-score } \\
\hline NDE & 1.433 & (1.380 to 1.488$)$ & $<0.001$ & 1.204 & (0.883 to 1.641$)$ & 0.241 \\
\hline NIE & 1.001 & (0.996 to 1.007 ) & 0.635 & 1.000 & (0.999 to 1.001 ) & 0.659 \\
\hline \multicolumn{7}{|l|}{ WHtRt } \\
\hline NDE & 1.455 & (1.288 to 1.643$)$ & $<0.001$ & 1.203 & (1.005 to 1.441$)$ & 0.045 \\
\hline NIE & 0.991 & (0.978 to 1.004$)$ & 0.183 & 1.000 & (0.997 to 1.003$)$ & 0.996 \\
\hline \multicolumn{7}{|l|}{ WC } \\
\hline NDE & 1.456 & (0.866 to 2.449$)$ & 0.156 & 1.204 & (0.970 to 1.495$)$ & 0.093 \\
\hline NIE & 0.996 & (0.992 to 1.000$)$ & 0.045 & 0.998 & (0.995 to 1.001$)$ & 0.135 \\
\hline
\end{tabular}

*Adjusted for sex, ethnicity, caesarean, firstborn, smoke in utero, smoke infancy and breast feeding. 
to consider potential bias due to misclassification of the mediator. BMI, WHtR and WC are proxies of body fat, and do not distinguish as well between fat and lean mass compared with objective measures such as dual energy X-ray absorptiometry and bioimpedance analysers. ${ }^{1538}$ However, a strength of our study is that more than one measure of bodyweight was tested, and these measures are quick and easy to administer in various settings. In addition, BMI scores were standardised by age and sex and similar results were found across all three bodyweight measures.

There are limitations to this study inherent to its design. Faceto-face interviews, used extensively in the MCS, are particularly prone to coverage and non-response biases..$^{39}$ Socially patterned missingness was apparent in our data, which may have diluted the association between socioeconomic position, covariates and non-allergic asthma. The vast majority of missing data (97.1\%) were due to non-response in waves 4 and 5 . This pattern of attrition has been noted previously within the MCS and non-response weights have been designed to counter differential bias, ${ }^{24}$ and were applied in this study. In many instances, subjective methods of self-reporting or proxy-reporting were used to capture information. Detection of non-allergic asthma in particular relied on maternal reports rather than a clinical diagnosis or an objective measure, likely adding some unmeasurable misclassification bias to our outcome measure. ${ }^{5}$ Objective measures, such as a skin prick test for atopy, would be more a reliable measure in this instance. ${ }^{17}$ In addition, self-reporting of smoking in pregnancy is known to lead to underestimation. ${ }^{40}$ Nonetheless, the methods employed meant that a multitude of risk factors were available on a large and contemporary longitudinal sample. In total, non-allergic asthma was identified in $7.0 \%$ of the productive singleton cohort at age 7; a similar proportion to estimates using objective measures in previous research. ${ }^{4}$

This research shows that socioeconomic disadvantage and adiposity are both important, yet independent, risk factors for non-allergic asthma. The findings highlight the multidimensional approach needed to disrupt the trajectory leading to this respiratory condition. While the need for population-wide interventions to tackle childhood obesity in the UK, such as the National Child Measurement Programme, ${ }^{41}$ is not disputed, broader and earlier action to tackle social inequity is an unavoidable prerequisite to alleviating the burden of this chronic condition. In addition, this research adds to the literature showing that additional or alternative measures of bodyweight, aside from BMI, are

\section{What is already known on this subject}

- Socioeconomic position and adiposity both relate to non-allergic asthma in childhood.

- Whether adiposity accounts for socioeconomic differences in childhood asthma is unknown.

\section{What this study adds}

- Using prospective cohort data, we found that bodyweight did not alter the effect of socioeconomic position on subsequent non-allergic asthma in childhood.

- The results suggest that improving socioeconomic conditions and promoting healthy weight are both important in reducing the development of non-allergic asthma in early to mid-childhood. useful when monitoring adiposity. ${ }^{342}$ High and low WHtR, in particular, should be measured when considering risk of future non-allergic asthma in paediatric populations. ${ }^{15}$

Acknowledgements We thank Professor Bianca De Stavola for her guidance on the analysis technique used in this paper.

Contributors KML designed the study, cleaned and analysed the data, and drafted and revised the paper. JM supervised the study, revised the study design and revised the paper. HP revised the paper. All authors gave final approval to the article.

Funding This work was supported by the Medical Research Council (grant number MR/N013867/1).

Competing interests None declared.

Ethics approval Ethical approval was granted and consent gained for all waves of the MCS by those responsible for the study.

Provenance and peer review Not commissioned; externally peer reviewed

Open Access This is an Open Access article distributed in accordance with the terms of the Creative Commons Attribution (CC BY 4.0) license, which permits others to distribute, remix, adapt and build upon this work, for commercial use, provided the original work is properly cited. See: http://creativecommons.org/licenses/by/4.0/

(C) Article author(s) (or their employer(s) unless otherwise stated in the text of the article) 2018. All rights reserved. No commercial use is permitted unless otherwise expressly granted.

\section{REFERENCES}

1 Boodhna G, Hall J. 2010 Health Survey for England: Chapter 4 Respiratory symptoms and asthma in children. London: The Health and Social Care Information Centre, 2011.

2 Mukherjee M, Stoddart A, Gupta RP, et al. The epidemiology, healthcare and societal burden and costs of asthma in the UK and its member nations: analyses of standalone and linked national databases. BMC Med 2016;14:113.

3 Milton B, Whitehead M, Holland P, et al. The social and economic consequences of childhood asthma across the lifecourse: a systematic review. Child Care Health Dev 2004;30:711-28.

4 Galobardes B, Granell R, Sterne J, et al. Childhood wheezing, asthma, allergy, atopy, and lung function: different socioeconomic patterns for different phenotypes. Am J Epidemiol 2015:182:763-74.

5 Strina A, Barreto ML, Cooper PJ, et al. Risk factors for non-atopic asthma/wheeze in children and adolescents: a systematic review. Emerg Themes Epidemio/ 2014;11:5.

6 Rönmark E, Jönsson E, Platts-Mills T, et al. Different pattern of risk factors for atopic and nonatopic asthma among children--report from the Obstructive Lung Disease in Northern Sweden Study. Allergy 1999;54:926-35.

7 de Meer G, Reijneveld SA, Brunekreef B. Wheeze in children: the impact of parental education on atopic and non-atopic symptoms. Pediatr Allergy Immunol 2010:21:823-30

8 Guibas GV, Manios Y, Xepapadaki P, et al. The obesity-asthma link in different ages and the role of body mass index in its investigation: findings from the Genesis and Healthy Growth Studies. Allergy 2013;68:1298-305.

9 Holguin F, Bleecker ER, Busse WW, et al. Obesity and asthma: an association modified by age of asthma onset. J Allergy Clin Immunol 2011;127:1486-93.

10 Stuart B, Panico L. Early-childhood BMI trajectories: evidence from a prospective, nationally representative British cohort study. Nutr Diabetes 2016:6:e198.

11 Panico L, Stuart B, Bartley M, et al. Asthma trajectories in early childhood: identifying modifiable factors. PLoS One 2014;9:e111922.

12 van Gent R, van der Ent CK, Rovers MM, et al. Excessive body weight is associated with additional loss of quality of life in children with asthma. J Allergy Clin Immunol 2007:119:591-6.

13 Basagaña X, Sunyer J, Kogevinas M, et al. European Community Respiratory Health Survey. Socioeconomic status and asthma prevalence in young adults: the European Community Respiratory Health Survey. Am J Epidemiol 2004;160:178-88.

14 Musaad SM, Patterson T, Ericksen M, et al. Comparison of anthropometric measures of obesity in childhood allergic asthma: central obesity is most relevant. J Allergy Clin Immunol 2009:123:1321-7.

15 Yiallouros PK, Lamnisos D, Kolokotroni O, et al. Associations of body fat percent and body mass index with childhood asthma by age and gender. Obesity 2013:21:E474-E82

16 Bibi H, Shoseyov D, Feigenbaum D, et al. The relationship between asthma and obesity in children: is it real or a case of over diagnosis? J Asthma 2004:41:403-10.

17 García-Marcos L, Castro-Rodríguez JA, Suarez-Varela MM, et al. A different pattern of risk factors for atopic and non-atopic wheezing in 9-12-year-old children. Pediatr Allergy Immunol 2005;16:471-7.

18 VanderWeele TJ. Mediation analysis: a practitioner's guide. Annu Rev Public Health 2016;37:17-32. 
19 VanderWeele TJ, Chiba Y. Sensitivity analysis for direct and indirect effects in the presence of exposure-induced mediator-outcome confounders. Epidemiol Biostat Public Health 2014;11:e9027.

20 Plewis I. The millennium cohort study: technical report on sampling (4th Edition) Centre for Longitudinal Studies, Institute of Education: London, UK, 2007.

21 Joshi $\mathrm{H}$, Fitzsimons E. The Millennium Cohort Study: the making of a multi-purpose resource for social science and policy. Longit Life Course Stud 2016;7:22.

22 Hansen K. Millennium Cohort Study: A Guide to the datasets (Eight Edition), First Second, Third, Fourth and Fifth Surveys. London, UK: Centre for Longitudinal Studies, Institute of Education University of London, 2014.

23 Pekkanen J, Lampi J, Genuneit J, et al. Analyzing atopic and non-atopic asthma. Eur J Epidemiol 2012;27:281-6.

24 Mostafa T. Millennium cohort study technical report on response in sweep 5 (age 11): Centre for Longitudinal Studies, 2014.

25 The UK Data Service. Series: Millennium Cohort Study. 2016 https://discover. ukdataservice.ac.uk/series/?sn=2000031.

26 ISAAC tools. International Study of Asthma and Allergies in Childhood. 2015 http:// isaac.auckland.ac.nz/resources/tools.php?menu=tools1.

27 Wright CM, Booth IW, Buckler JM, et al. Growth reference charts for use in the United Kingdom. Arch Dis Child 2002;86:11-14.

28 . Stata Statistical Software: Release 13 StataCorp. College Station, TX: StataCorp LP, 2013.

29 Daniel RM, De Stavola BL, Cousens SN. Gformula: Estimating causal effects in the presence of time-varying confounding or mediation using the g-computation formula. Stata Journal 2011;11:479-517.

30 Taylor-Robinson DC, Pearce A, Whitehead M, et al. Social inequalities in wheezing in children: findings from the UK Millennium Cohort Study. Eur Respir J 2016:47:818-28.

31 Gilliland FD, Berhane K, Islam T, et al. Obesity and the risk of newly diagnosed asthma in school-age children. Am J Epidemiol 2003;158:406-15.
32 Visness CM, London SJ, Daniels JL, et al. Association of childhood obesity with atopic and nonatopic asthma: results from the National Health and Nutrition Examination Survey 1999-2006. J Asthma 2010;47:822-9.

33 Appleton SL, Adams RJ, Wilson DH, et al. North West Adelaide Health Study Team. Central obesity is associated with nonatopic but not atopic asthma in a representative population sample. J Allergy Clin Immunol 2006;118:1284-91.

34 Papoutsakis C, Chondronikola M, Antonogeorgos G, et al. Associations between central obesity and asthma in children and adolescents: a case-control study. J Asthma 2015;52:128-34.

35 Ashwell M, Hsieh SD. Six reasons why the waist-to-height ratio is a rapid and effective global indicator for health risks of obesity and how its use could simplify the international public health message on obesity. Int J Food Sci Nutr 2005;56:303-7.

36 Wang A, Arah OA. G-computation demonstration in causal mediation analysis. Eur $J$ Epidemiol 2015:30:1119-27.

37 Mebrahtu TF, Feltbower RG, Parslow RC. Effects of birth weight and growth on childhood wheezing disorders: findings from the Born in Bradford Cohort. BMJ Open 2015; 5:e009553.

38 Ness AR, Leary SD, Mattocks C, et al. Objectively measured physical activity and fat mass in a large cohort of children. PLoS Med 2007;4:e97.

39 Bowling A. Mode of questionnaire administration can have serious effects on data quality. J Public Health 2005;27:281-91.

40 Shipton D, Tappin DM, Vadiveloo T, et al. Reliability of self reported smoking status by pregnant women for estimating smoking prevalence: a retrospective, cross sectional study. BMJ 2009;339:b4347

41 Copley V, Bray C. National child measurement programme: changes in children's body mass index between 2006/07 and 2015/16: Public Health England London, 2017.

$42 \mathrm{McC}$ arthy HD, Ashwell M. A study of central fatness using waist-to-height ratios in UK children and adolescents over two decades supports the simple message--'keep your waist circumference to less than half your height'. Int J Obes 2006;30:988-92. 